\title{
Changes of tropical precipitation and convective structure under global warming projected by CMIP5 model simulations
}

\author{
Hsiao-Wei Liu ${ }^{1,3}$, Jia-Yuh $\mathrm{Yu}^{1, *}$, and Chao-An Chen ${ }^{2}$ \\ ${ }^{1}$ Department of Atmospheric Sciences, National Central University, Taoyuan City, Taiwan \\ ${ }^{2}$ Research Center for Environmental Changes, Academia Sinica, Taipei City, Taiwan \\ ${ }^{3}$ National Science and Technology Center for Disaster Reduction, New Taipei City, Taiwan
}

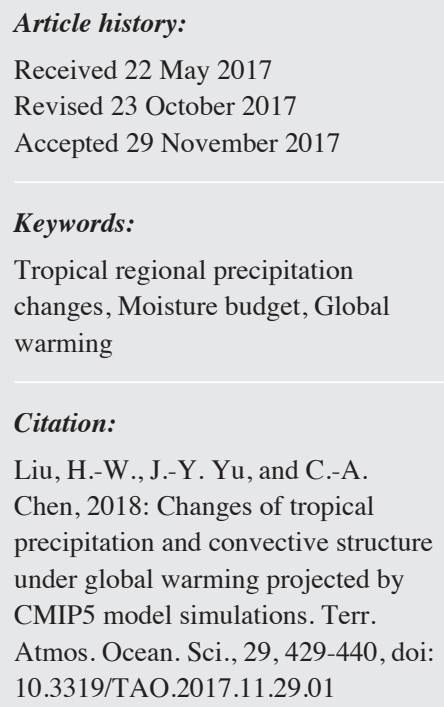

\begin{abstract}
Regional changes of precipitation intensity, convective structure and column water vapor $(\mathrm{CWV})$ in the Tropics are examined using climate model simulation outputs archived in the Coupled Model Intercomparison Project, phase 5 (CMIP5) for the representative concentration pathway 8.5 (RCP8.5) experiments. Under global warming, CWV increases homogeneously in space following the Clausius-Clapeyron scaling. In contrast, precipitation changes exhibit marked regional discrepancies with a mix of positive and negative anomalies in both mean ascending and descending regions. A moisture budget analysis indicates that changes of tropical precipitation are controlled mainly by the dynamic effect $\left(-\left\langle\omega^{\prime} \partial_{p} \bar{q}\right\rangle\right)$, with a secondary contribution from the thermodynamics effect $\left(-\left\langle\bar{\omega} \partial_{p} q^{\prime}\right\rangle\right)$. Precipitation changes comply with the "wet-get-wetter" or "dry-get-drier" mechanism over the regions where dynamic and thermodynamic effects work together, accounting for about two thirds of the total tropical area. Examining changes of convection structure further show that regions with negative precipitation anomalies must be accompanied by the weakening of convection in the entire troposphere. Convection structure changes attributing to positive precipitation anomalies, nonetheless, appear to be very different depending on the regions. In the mean ascending region, the positive precipitation anomaly is associated with the deepening of convection. In the mean descending region, the positive precipitation anomaly is a result of proportionally enhanced convection within the troposphere. The above findings are based on area-mean results. Further details may emerge when viewing convection and precipitation changes at local scales.
\end{abstract}

\section{INTRODUCTION}

Changes in large-scale water cycle are an expected consequence of anthropogenic atmospheric warming. As the climate warms, the atmospheric water-holding capacity also increases and, as a result, the water vapor in the troposphere shows a concurrent increase even though the relative humidity appears relatively unchanged (Trenberth et al. 2003; Zhou et al. 2011; Liu and Yu 2016). Over the past decade, simulation outputs from coupled climate models have been utilized to project tropical circulation and rainfall changes under anthropogenic global warming and these past studies have yielded a number of interesting findings. For example, Held and Soden (2006) used CMIP3 (Coupled Model In-

\footnotetext{
* Corresponding author

E-mail:jiayuh@atm.ncu.edu.tw
}

tercomparison Project, phase 3) archive to look for robust responses of the water cycle to global warming. They found that the thermodynamic relationship between warming and moisture is generally determined according to the ClausiusClapeyron relation, i.e., approximately $6-7 \%$ increase in moisture-holding capacity for each $1^{\circ} \mathrm{C}$ increase in air temperature (Wentz et al. 2007; O'Gorman and Muller 2010). In contrast to moisture, climate model simulations showed an increased rate of global-mean precipitation of only about $1-3 \%$ in response to $1^{\circ} \mathrm{C}$ warming (Allen and Ingram 2002; Held and Soden 2006; Stephens and Ellis 2008).

The above discrepancy between moisture and precipitation changes implies that changes of precipitation in response to atmospheric warming must involve complex interactions between thermodynamic and dynamic effects. 
Based on this hypothesis, some studies examined dynamic and thermodynamic controls on precipitation changes using simple general circulation models (Neelin et al. 2003; Chou and Neelin 2004) or climate models in CMIP3 (Vecchi and Soden 2007; Chou et al. 2009; Seager et al. 2010; Muller and O'Gorman 2011), and several hypotheses have been proposed to explain such changes. For example, the "richget-richer" (or "wet-get-wetter") and "upped ante" mechanisms (Neelin et al. 2003; Chou and Neelin 2004; Chou et al. 2009) demonstrated that precipitation tends to increase near the centers of convective regions while decrease at the margins of convective regions. The hypothesis behind these arguments is that the increase of temperature ups the ante for convection. In the center of convective regions, the upped convective ante is easily met due to abundant moisture supply, resulting in enhanced convection and precipitation. At the convective margins, increase of moisture is partially opposed by dry advection from non-convective regions such that the upped convective ante is difficult to be reached, resulting in decreased convection and precipitation. Recently, Johnson and Xie (2010), Xie et al. (2010), and Huang et al. (2013) proposed the "warmer-get-wetter" mechanism to account for changes of tropical precipitation under global warming. They found that rainfall changes generally follow the pattern of tropical SST warming, especially over the equatorial Pacific regions where the maximum tropical SST warming often occurs.

Since the above hypotheses were mostly based on simulations from earlier versions of coupled climate models archived in CMIP3 (Meehl et al. 2007), it is speculated that the model resolutions and physics might be too coarse to produce a reliable projection of tropical precipitation changes under global warming. To elaborate, Fig. 1 shows two examples of simulation differences between models in CMIP3 and CMIP5 (Coupled Model Intercomparison Project, phase 5). In the first example (NASA GISS model), the model resolution is doubled from $4^{\circ} \times 5^{\circ}$ in GISS-ER (CMIP3) to $2^{\circ} \times 2.5^{\circ}$ in GISS-E2-R (CMIP5), along with additions of chemistry-aerosol interaction and indirect aerosol effect (Schmidt et al. 2014). In the second example (French CNRM model), the model resolution is doubled from $2.8^{\circ} \times 2.8^{\circ}$ in CNRM-CM3 (CMIP3) to $1.4^{\circ} \times 1.4^{\circ}$ in CNRM-CM5 (CMIP5), along with an improved radiation scheme and the treatments of tropospheric and stratospheric aerosols (Voldoire et al. 2013). As shown in Fig. 1, while the mean patterns of tropical convective zone (denoted by the areas enclosed by solid contours) are similar between GISS-ER (Figs. 1a - b) and GISS-E2-R (Figs. 1c - d), marked differences in regional precipitation changes occur for both JJA and DJF seasons. In particular, the significant positive precipitation anomalies in the equatorial eastern Pacific simulated by GISS-E2-R are not seen in GISS-ER. Besides, the position and intensity of regional precipitation changes are also somewhat different in the western Pacific and Indian warm pool regions. Similar discrepancies exist in CNRM-CM3 (Figs. 1e - f) and CNRM-CM5 (Figs. 1g - h) simulations although their magnitude difference are less striking compared to those in GISS models. The above findings clearly indicate that, under a similar physical framework, coarse resolution climate models are unlikely to produce a reliable projection of regional precipitation changes under global warming, especially in the eastern Pacific regions where horizontal gradients of SST and precipitation are much larger compared to the warm pool regions such as the western Pacific and Indian Ocean.

Recently, Chen et al. (2016) combined 16 CMIP3 and 16 CMIP5 model simulations to examine future changes of tropical circulation (convection) over convective regions with positive precipitation anomalies. Two types of convection enhancement were indentified: the top-heavy (deep) and bottom-heavy (shallow) convection. They further argued that the top-heavy (deep) convection is linked to a more stable atmosphere and a weakened circulation due to increased gross moist stability; while the bottom-heavy (shallow) convection is associated with to a more unstable atmosphere and a strengthened circulation due to decreased gross moist stability.

In this study, we expand the studied domain to include the ITCZ and non-ITCZ regions and to reexamine tropical regional precipitation changes based on modern climate model simulation outputs archived in CMIP5 (Taylor et al. 2012), with a special emphasis on contrasting the different roles of dynamic and thermodynamic effects in controlling precipitation changes. Section 2 introduces the data and methodology used in this study. Section 3 examines changes of tropical column water vapor and precipitation from both global tropics and regional points of view. The mechanisms responsible for regional precipitation changes are discussed in this section based on a simple analysis of the anomalous moisture budget equation. Major findings and suggestions are concluded in section 4 .

\section{DATA AND METHODOLOGY}

The data products used in this study include monthly mean fields of winds, specific humidity, evaporation, precipitation, and column water vapor during the period from 2006 to 2099 derived from coupled climate models archived in CMIP5 for the representative concentration pathway 8.5 (RCP8.5) experiments. To better reproduce regional precipitation changes in the Tropics, only the 17 CMIP5 models with horizontal resolution of $2.8^{\circ} \times 2.8^{\circ}$ or finer are employed in this study (see Table 1 for a summary of these models). To facilitate the moisture budget analysis, all model outputs were re-gridded onto a common horizontal resolution of $2.5^{\circ}$ $\times 2.5^{\circ}$, with 17 vertical levels from $1000-10 \mathrm{hPa}$.

The vertically-integrated moisture equation can be written as 

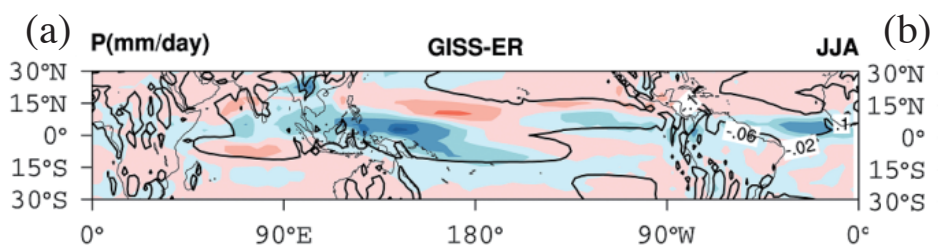

(c) $\mathbf{P}(\mathrm{mm} /$ day $)$

$180^{\circ}$

$0^{\circ}$
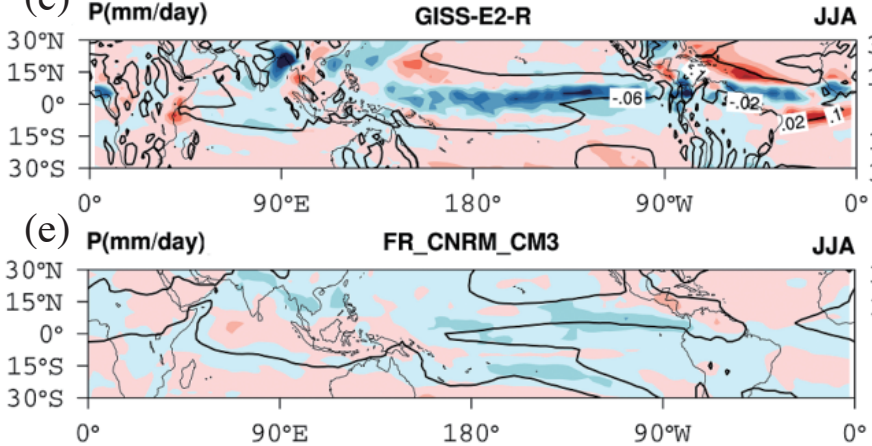

$0^{\circ}(\mathrm{f})$

(d) $P(m m / d a y)$

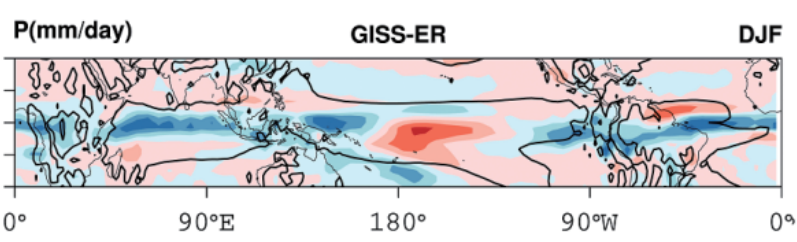

$30^{\circ} \mathrm{N}$

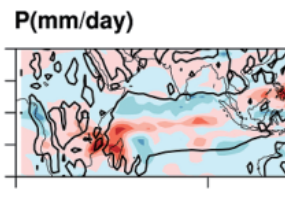

(f)

$90^{\circ} \mathrm{F}$

$180^{\circ}$

09
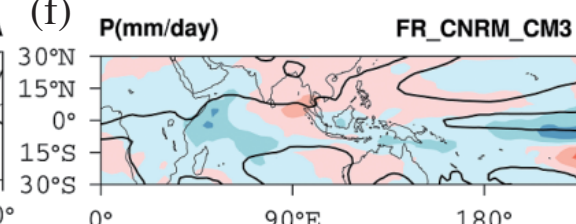

FR_CNRM_CM3

(h) $\mathbf{P}(\mathrm{mm} /$ day $)$
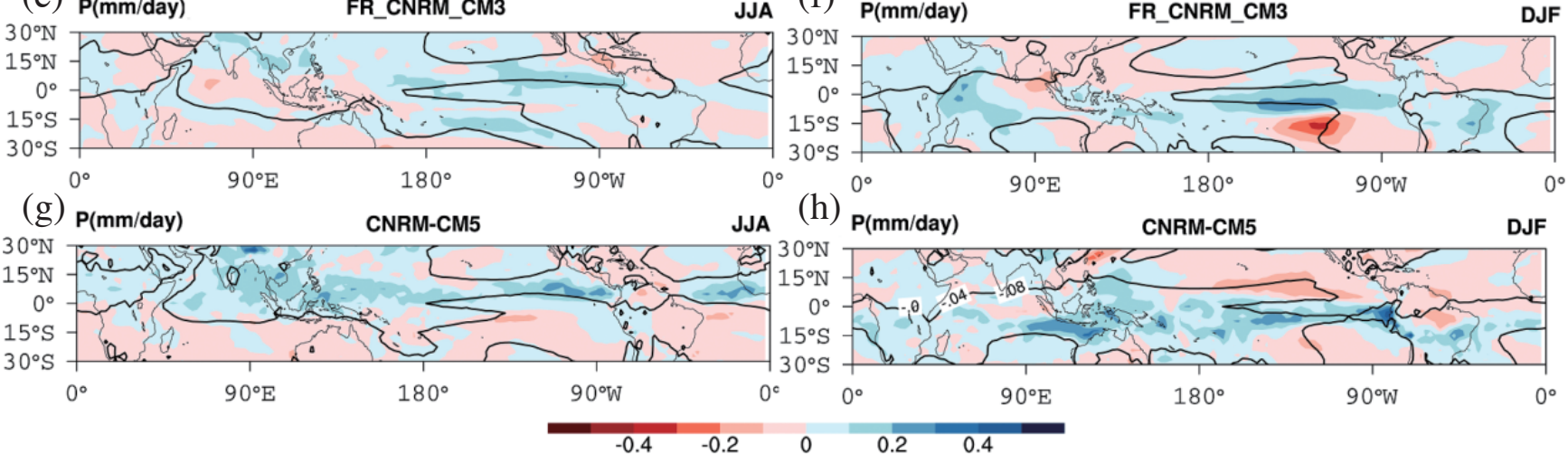

Fig. 1. The first row shows simulated tropical precipitation changes (shadings, in mm day ${ }^{-1}$ decade $^{-1}$ ) during the period $2006-2099$ in (a) northern summer (JJA, left panel) and (b) winter (DJF, right panel), respectively, projected by GISS-ER $\left(4^{\circ} \times 5^{\circ}\right)$ in CMIP3 under A2 scenario; the second row (c) and (d) shows the corresponding precipitation changes during the period $2006-2099$ projected by GISS-E2-R $\left(2^{\circ} \times 2.5^{\circ}\right)$ in CMIP5 under RCP8.5 scenario. Similarly, the third (e) and (f) and fourth rows (g) and (h) show precipitation changes for CNRM-CM3 $\left(2.8^{\circ} \times 2.8^{\circ}\right)$ in CMIP3 and CNRM-CM5 $\left(1.4^{\circ} \times 1.4^{\circ}\right)$ in CMIP5, respectively. The solid contours mark the positions where the $500 \mathrm{hPa}$ mean vertical velocity is zero.

Table 1. A list of 17 coupled atmosphere-ocean climate models archived in the CMIP5 used in this study.

\begin{tabular}{|c|c|}
\hline Model Name & Modeling Center (or Group) \\
\hline ACCESS1.0 & Commonwealth Scientific and Industrial Research Organization (CSIRO) and Bureau of Meteorology (BOM), Australia \\
\hline BCC-CSM1.1 & Beijing Climate Center, China Meteorological Administration \\
\hline CanESM2 & Canadian Centre for Climate Modeling and Analysis \\
\hline CCSM4 & National Center for Atmospheric Research \\
\hline CESM1(BGC) & Community Earth System Model Contributors \\
\hline CNRM-CM5 & Centre National de Recherches Meteorologiques/Centre Europeen de Recherche et Formation Avancee en Calcul Scientifique \\
\hline FGOALS-s2 & LASG, Institute of Atmospheric Physics, Chinese Academy of Sciences and CESS, Tsinghua University \\
\hline FIO-ESM & The First Institute of Oceanography, SOA, China \\
\hline GFDL-CM3 & NOAA Geophysical Fluid Dynamics Laboratory \\
\hline GISS-E2-R & NASA Goddard Institute for Space Studies \\
\hline HadGEM2-CC & Met Office Hadley Centre (additional HadGEM2-ES realizations contributed by Instituto Nacional de Pesquisas Espaciais) \\
\hline IPSL-CM5A-MR & Institut Pierre-Simon Laplace \\
\hline MIROC-ESM & $\begin{array}{l}\text { Japan Agency for Marine-Earth Science and Technology, Atmosphere and Ocean Research Institute (The University of Tokyo), } \\
\text { and National Institute for Environmental Studies }\end{array}$ \\
\hline MIROC5 & $\begin{array}{l}\text { Atmosphere and Ocean Research Institute (The University of Tokyo), National Institute for Environmental Studies, and Japan } \\
\text { Agency for Marine-Earth Science and Technology }\end{array}$ \\
\hline MPI-ESM-LR & Max-Planck-Institut für Meteorologie (Max Planck Institute for Meteorology) \\
\hline MRI-CGCM3 & Meteorological Research Institute \\
\hline NorESM1-M & Norwegian Climate Centre \\
\hline
\end{tabular}


$\frac{\partial}{\partial t}\langle q\rangle=-\langle\mathbf{v} \cdot \nabla q\rangle-\left\langle\omega \partial_{p} q\right\rangle+E-P$

where $q$ is the specific humidity in energy unit $\left(\mathrm{J} \mathrm{kg}^{-1}\right)$ by absorbing the heat of condensation $\left(L=2.5 \times 10^{6} \mathrm{~J} \mathrm{~kg}^{-1}\right), \mathbf{v}$ denotes the horizontal wind vector, $\omega$ is the pressure velocity, and $E$ and $P$ represent evaporation and precipitation (both in energy units with the following transformation: $1 \mathrm{~mm}^{-1 a y^{-1}}$ $=29.84 \mathrm{~W} \mathrm{~m}^{-2}$ ), respectively. The brackets in Eq. (1) represent a mass integration over the entire troposphere from $p_{T}=$ $100 \mathrm{hPa}$ to $p_{0}=1000 \mathrm{hPa}$, which is defined as

\langle\rangle$=g^{-1} \int_{P_{o}}^{P_{T}}() d p$

where $g$ is the gravitational constant.

Following Chou et al. (2009), assuming the change of mean state vertical motion is negligible compared to its perturbation counterpart, the precipitation anomaly can be estimated by the following approximation:

$P^{\prime}=-\left\langle\bar{\omega} \partial_{p} q^{\prime}\right\rangle-\left\langle\omega^{\prime} \partial_{p} \bar{q}\right\rangle-\langle\mathbf{v} \cdot \nabla q\rangle^{\prime}+E^{\prime}+$ residual_q

where $\left(^{-}\right)$denotes the climatology averaged over the entire data period from 2006 - 2099 and ( )' represents anomaly (or perturbation) between the two periods: 2006 - 2015 and 2090 - 2099. The physical terms on right hand side of Eq. (3) represents all the contributing effects responsible for precipitation anomaly, including vertical moisture transport anomaly due to change in moisture stratification $\left(-\left\langle\bar{\omega} \partial_{p} q^{\prime}\right\rangle\right)$, vertical moisture transport anomaly due to change in convection perturbation $\left(-\left\langle\omega^{\prime} \partial_{p} \bar{q}\right\rangle\right)$, change in horizontal moisture transport $\left(-\langle\mathbf{v} \cdot \nabla q\rangle^{\prime}\right)$, and change in evaporation $\left(E^{\prime}\right)$. The last term (residual_q) denotes contributions from nonlinear transient eddies which are generally not part of the physical solution as their magnitudes are much smaller compared to the other terms. In the following analysis, multi-model means of the 17 CMIP5 models outputs are taken in the budget analysis, focusing on the tropical oceanic domain $\left(30^{\circ} \mathrm{N}-30^{\circ} \mathrm{S}\right)$ to avoid complexity caused by land topography.

\section{MULTI-MODEL ENSEMBLE RESULTS}

Figure 2 shows yearly changes of column water vapor (CWV) and precipitation during the period from 2006 - 2099 projected by the multi-model means of 17 CMIP5 models over the mean ascending (upper panel) and descending (lower panel) regions. The zero contours of multi-model mean pressure velocity at $500 \mathrm{hPa}$ (i.e., $\bar{\omega}_{500}=0$ ) are superimposed onto the maps to mark the boundaries between mean ascending and descending regions (see the thick solid curves in Fig. 2), similar to Chen et al. (2016). It is found that, over the mean ascending region, CWV increases by about $30 \%$
(40 - $52 \mathrm{~mm}$ ) from 2006 - 2099. Since the multi-model mean tropical surface warming projected by the RCP8.5 scenario is about $4{ }^{\circ} \mathrm{C}$ over the same period, this corresponds to about $7 \%$ increase in $\mathrm{CWV}$ per unit ${ }^{\circ} \mathrm{C}$ of atmospheric warming, consistent with the Clausius-Clapeyron scaling (Held and Soden 2006). Similar results occur over the mean descending region as the column water vapor increases by almost the same fraction (about 29\%) from $31 \mathrm{~mm}$ in 2006 to $40 \mathrm{~mm}$ in 2099. On average, the rate of increased CWV is about 1.2 $\mathrm{mm}$ decade $^{-1}$ in the Tropics.

In contrast to $\mathrm{CWV}$, precipitation changes projected by the multi-model means of 17 CMIP5 models are modest both in the mean ascending and descending regions although there seems to be a slight increase (decrease) trend of precipitation intensity over the mean ascending (descending) region. The above results suggest that a large portion of the increased water vapor must be contained in the atmosphere as the moisture-holding capacity of atmosphere increases in a warmer environment (Stephens and Ellis 2008). If one views the ratio of precipitation intensity over CWV (i.e., $P /$ $\mathrm{CWV}$ ) as a measure of precipitation efficiency, a smaller value of $P / C W V$ implies a less efficiency in producing precipitation. Also shown in Fig. 2 (see green curves), while values of $P / C W V$ are much greater in the mean ascending region (ranging from 0.18 in 2006 to 0.15 in 2099) compared to those in the mean descending region (ranging from 0.05 in 2006 to 0.03 in 2099), both regions show a consistent decreasing trend of $P / \mathrm{CWV}$ (precipitation efficiency) under global warming.

To understand why the area-mean precipitation changes are only modest in the Tropics, Fig. 3 displays spatial patterns of the precipitation trends (color shadings, in units of mm day ${ }^{-1}$ decade $^{-1}$ ) and the associated $\bar{\omega}_{500}$ field (contours) derived from multi-model means of 17 CMIP5 models outputs from 2006 - 2099 (patterns of individual model are displayed and discussed in Appendix for reference). In the mean ascending region, positive and negative precipitation trends coexist, with the former's area coverage about twofold greater than the latter (26.9\% vs. $13.8 \%)$. A similar situation occurs in the mean descending region, yet with more area coverage of negative precipitation trends than positive trends $(37.8 \%$ vs. $21.4 \%)$. The fractional area coverage of each sub-region is summarized in Table 2 for reference. The strong cancelation between positive and negative precipitation trends leads to a very modest change of precipitation in these two regions. It appears that precipitation changes under global warming are much more complex compared to moisture changes, with the latter typically following the Clausius-Clapeyron scaling as shown in Fig. 2, as the former often involves strong interaction between dynamic and thermodynamic feedbacks (Chou and Neelin 2004; Held and Soden 2006; Chou et al. 2009; Chen et al. 2016).

To explore the mechanisms responsible for regional discrepancies of precipitation anomalies under global 
warming, a budget analysis of the precipitation anomaly Eq. (3) is carried out. Four sub-regions are analyzed separately according to the criteria implied by Fig. 3, which include: (a) the mean ascending region $\left(\bar{\omega}_{500}<0\right)$ with positive precipitation anomalies $\left(P^{\prime}>0\right)$, (b) the mean ascending region $\left(\bar{\omega}_{500}<0\right)$ with negative precipitation anomalies $\left(P^{\prime}<0\right)$, (c) the mean descending region $\left(\bar{\omega}_{500}>0\right)$ with positive precipitation anomalies $\left(P^{\prime}>0\right)$, and $(\mathrm{d})$ the mean descending region $\left(\bar{\omega}_{500}>0\right)$ with negative precipitation anomalies $\left(P^{\prime}<0\right)$. We note that sub-regions (a) and $(d)$ show precipitation changes obeying the hypotheses of "wetget-wetter" and "dry-get-drier", respectively; while sub-regions (b) and (c) do not. Here, the anomaly (or perturbation) field is derived by subtracting the averages over the last 10 years (2090 - 2099) from those over first 10 years (2006 2015).

(a) climatologically ascending region

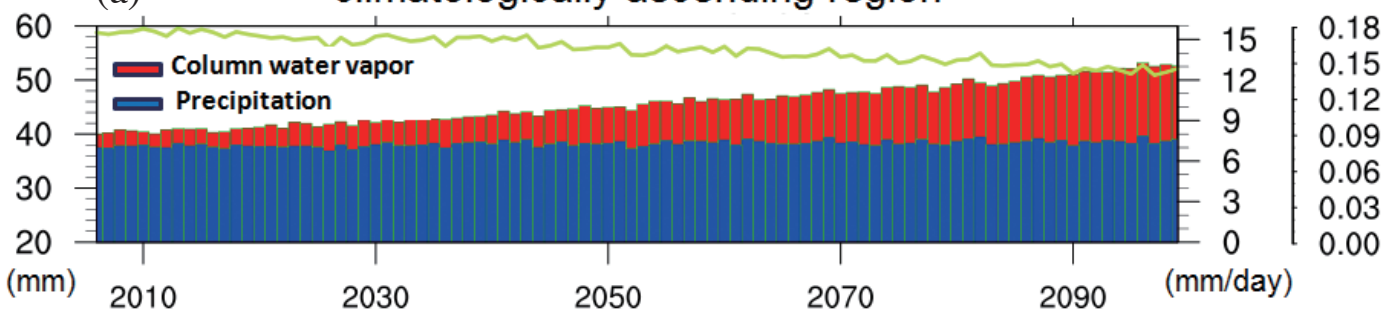

(b) climatologically descending region

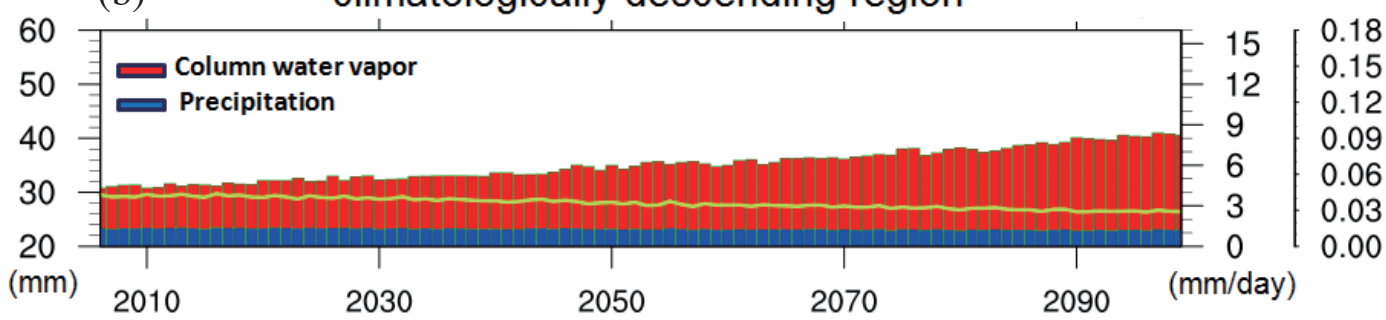

Fig. 2. The yearly time series of column water vapor (red, in unit of $\mathrm{mm}$ ) and precipitation intensity (blue, in unit of $\mathrm{mm} \mathrm{day}^{-1}$ ) in (a) mean ascending region and (b) mean descending region derived from the multi-model means of 17 CMIP5 models under the RCP8.5 scenario over the period 2006 - 2099. The ratio between precipitation and column water vapor (green) is also displayed to highlight changes of precipitation effectiveness under global warming.

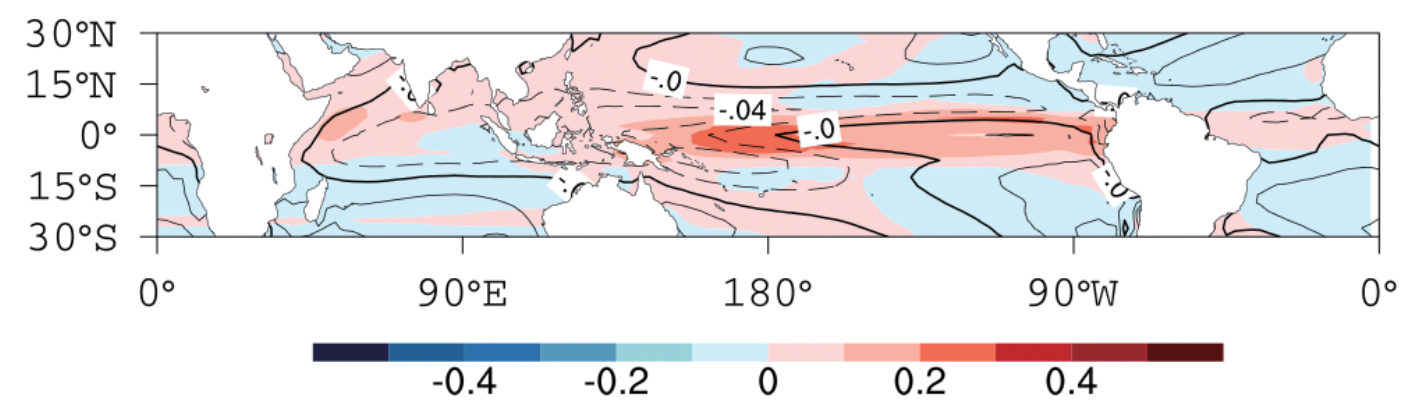

Fig. 3. Spatial patterns of precipitation intensity trend (color shadings, in units of $\mathrm{mm} \mathrm{day}^{-1} \mathrm{decade}^{-1}$ ) and pressure velocity climatology (contours, in units of $\mathrm{pa} \mathrm{s}^{-1}$ with a contour interval of $\left.0.02 \mathrm{pa} \mathrm{s}^{-1}\right)$ over tropical oceanic domain $\left(30^{\circ} \mathrm{S}-30^{\circ} \mathrm{N}\right)$ derived from the multi-model means of $17 \mathrm{CMIP} 5$ models under the RCP8.5 scenario over the period 2006 - 2099. The thick solid lines denote the $\bar{\omega} 500=0$ contours which separate the mean ascending region from the descending region.

Table 2. Fractional area coverage (in \%) for the four subregions (a) - (d) defined in section 3. Only the oceanic areas are considered in calculating the fractional area coverage.

\begin{tabular}{ccc}
\hline Sub-region & $P^{\prime}>0$ & $P^{\prime}<0$ \\
\hline $\bar{\omega}_{500}<0$ & (a) $26.9 \%$ & (b) $13.8 \%$ \\
$\bar{\omega}_{500}>0$ & (c) $21.4 \%$ & (d) $37.8 \%$ \\
\hline
\end{tabular}


Since the mean state property of vertical motion is employed as a categorization criterion for evaluating changes in precipitation, it is necessary to see whether this criterion might change significantly under global warming. As shown in Fig. 4, changes of $\bar{\omega}_{500}=0$ contours are very small during the period from 2005 - 2099. For instance, the ITCZ domain (denoted by the area enclosed by $\bar{\omega}_{500}=0$ contours) accounts for about $46.05 \%$ of the total tropical area over the first quarter-century of 2006 - 2025, and its size slightly increases to $46.55 \%$ over the last quarter-century of 2076 - 2099. This implies that the division of tropics into four sub-regions and the decomposition of moisture budget into anomaly Eq. (3) are physically reasonable.

The budget analysis results over the aforementioned sub-regions are displayed in Fig. 5. In the mean ascending region with positive precipitation anomaly (i.e., $\bar{\omega}_{500}<0$ and $P^{\prime}>0$ ), the positive precipitation anomaly (see Fig. 5a) appears to come mainly from the strengthening of convection $\left(-\left\langle\omega^{\prime} \partial_{p} \bar{q}\right\rangle>0\right)$, which is referred to as the dynamic effect, followed by a minor contribution from the enhancement of moisture stratification ( $\left.-\left\langle\bar{\omega} \partial_{p} q^{\prime}\right\rangle>0\right)$, which is referred to as the thermodynamic effect. In the mean ascending region with

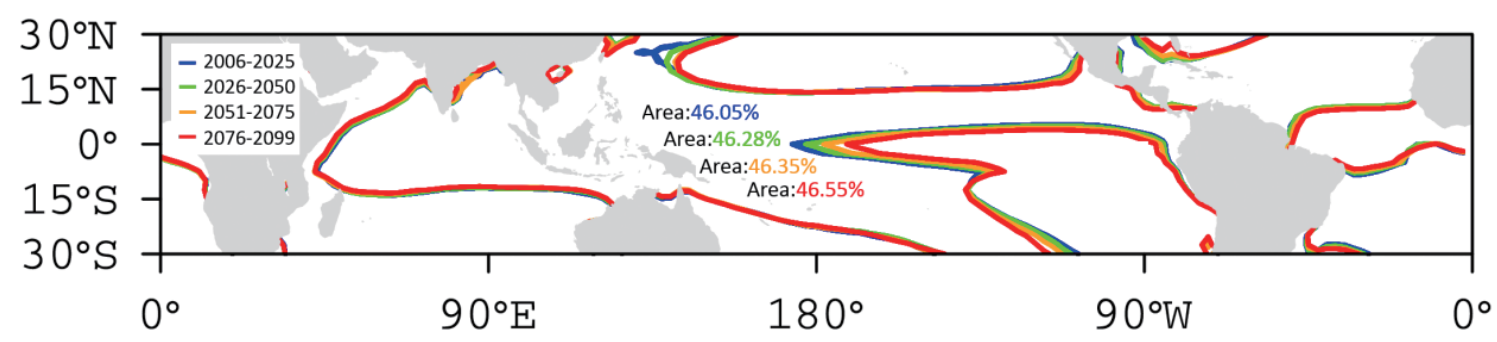

Fig. 4. Changes of the $\bar{\omega}_{500}=0$ contours (an indication of the ITCZ domain) in quarter century interval: 2006 - 2025 (blue), 2026 - 2050 (green), 2051 - 2075 (yellow), and 2076 - 2099 (red). The area coverage of ITCZ (in \%) in each quarter century is also displayed for comparison purpose.
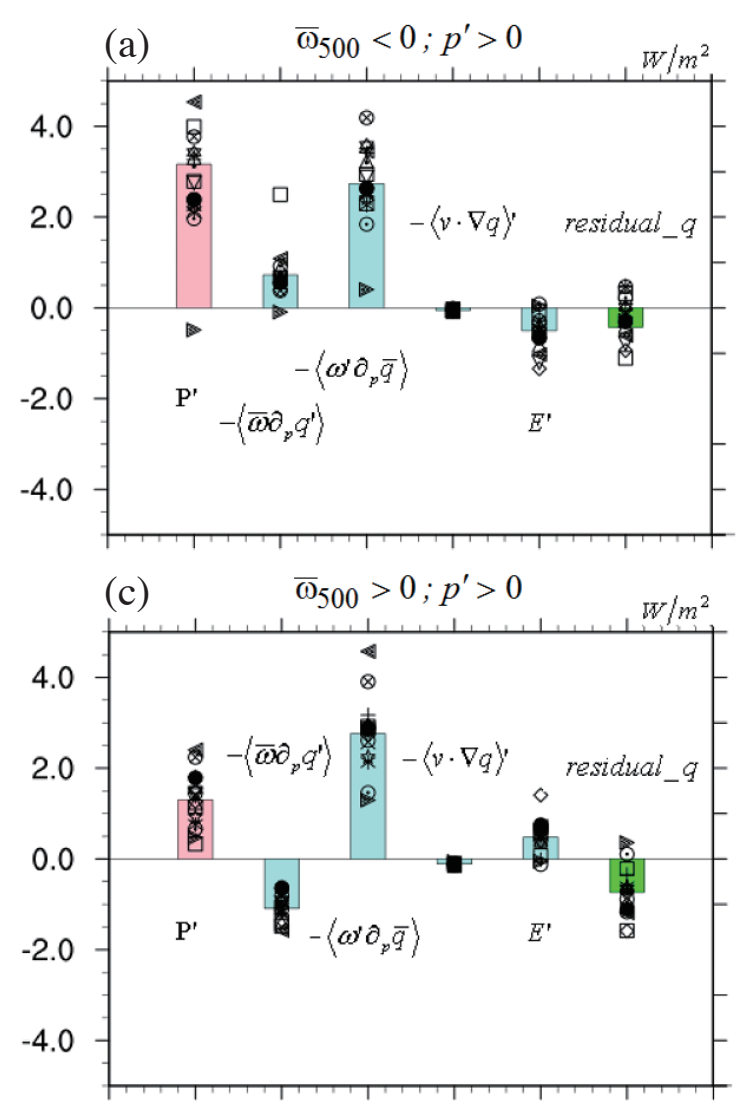

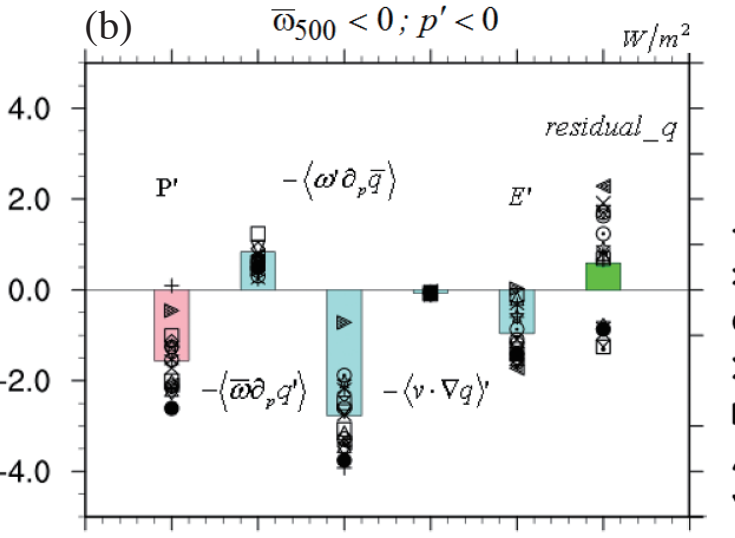

(d)

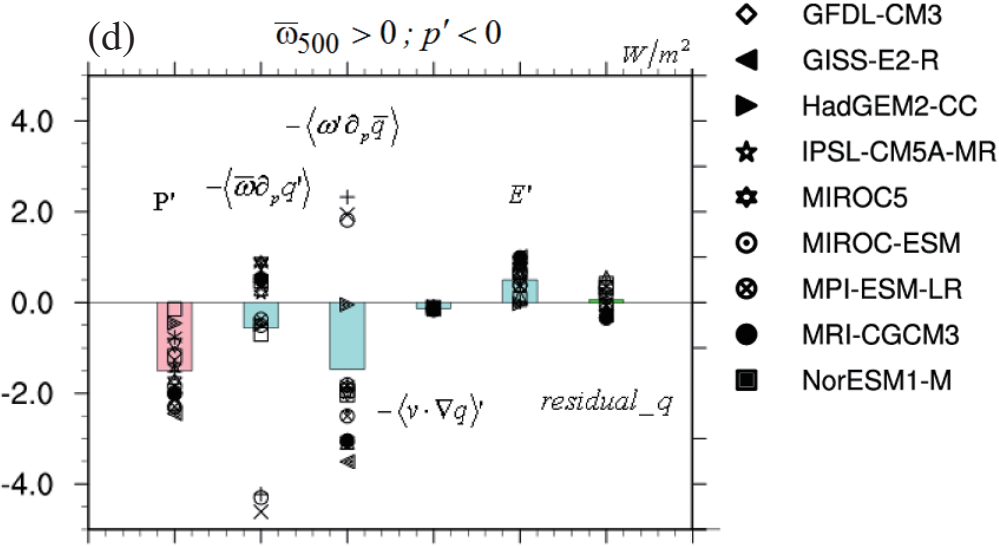

BCC-CSM1.1

CanESM2

CCSM4

CESM1-BGC

CNRM-CM5

FGOALS-s2

FIO-ESM

GFDL-CM3

GISS-E2-R

HadGEM2-CC

IPSL-CM5A-MR

MIROC5

MIROC-ESM
ACCESS1.0

Fig. 5. Term budget results for the precipitation anomalies in (a) mean ascending region with positive precipitation anomaly $\left(\bar{\omega}_{500}<0 ; P^{\prime}>0\right)$, (b) mean ascending region with negative precipitation anomaly $\left(\bar{\omega}_{500}<0 ; P^{\prime}<0\right)$, (c) mean descending region with positive precipitation anomaly $\left(\bar{\omega}_{500}>0 ; P^{\prime}>0\right)$, and (d) mean descending region with negative precipitation anomaly $\left(\bar{\omega}_{500}>0 ; P^{\prime}<0\right)$. All terms are in energy units $\left(\mathrm{W} \mathrm{m}^{-2}\right)$. The fractional area coverage (in \%) for each sub-domain from (a) - (d) is 26.9, 13.8, 21.4, and 37.8\%, respectively. 
negative precipitation anomaly (i.e., $\bar{\omega}_{500}<0$ and $P^{\prime}<0$ ), the negative precipitation anomaly (see Fig. $5 b$ ) is again coming mainly from the dynamic effect $\left(-\left\langle\omega^{\prime} \partial_{p} \bar{q}\right\rangle<0\right)$, which implies a weakening of convection. In contrast to Fig. 5a, the thermodynamic effect $\left(-\left\langle\bar{\omega} \partial_{p} q^{\prime}\right\rangle>0\right)$ here acts to partially offset the precipitation anomaly. Evaporation anomalies $\left(E^{\prime}\right)$ are small negatives over the two ascending sub-regions. Contributions from horizontal moisture advection anomaly $\left(-\langle v \cdot \nabla q\rangle^{\prime}\right)$ is very minimal.

In the mean descending region with positive precipitation anomaly (i.e., $\bar{\omega}_{500}>0$ and $P^{\prime}>0$ ), the positive precipitation anomaly (see Fig. 5c) is due to the strengthening of convection $\left(-\left\langle\omega^{\prime} \partial_{p} \bar{q}\right\rangle>0\right)$, with intensity partially offset by the thermodynamic effect $\left(-\left\langle\bar{\omega} \partial_{p} q^{\prime}\right\rangle\langle 0)\right.$ because of positive $\langle\bar{\omega}\rangle$. In the mean descending region with negative precipitation anomaly (i.e., $\bar{\omega}_{500}>0$ and $P^{\prime}<0$ ), the negative precipitation anomaly (see Fig. $5 \mathrm{~d}$ ) is mostly associated the weakening of convection $\left(-\left\langle\omega^{\prime} \partial_{p} \bar{q}\right\rangle<0\right)$, with an additional support from the thermodynamic effect $\left(-\left\langle\bar{\omega} \partial_{p} q^{\prime}\right\rangle\langle 0)\right.$. Evaporation anomalies $\left(E^{\prime}\right)$ are weakly positive over the two descending sub-regions, and the horizontal moisture advection anomaly $\left(-\langle v \cdot \nabla q\rangle^{\prime}\right)$ is again negligible. On average, sub-regions (a), (b), (c), and (d) account for 3.25, -1.5, 1.25 , and $-1.5 \mathrm{~W} \mathrm{~m}^{-2}$, respectively, of the total precipitating change (in energy unit). In additional to the area-mean budget shown above, we also demonstrate the geographical distribution of each budget term in Appendix B.

In summary, regional precipitation changes in the Tropics are controlled mainly by the dynamic effect $\left(-\left\langle\omega^{\prime} \partial_{p} \bar{q}\right\rangle\right)$ no matter over the mean ascending or descending regions. Tropical areas with positive (negative) precipitation anomalies must be accompanied by enhancement (weakening) of convection (i.e., $P^{\prime}$ and $-\left\langle\omega^{\prime} \partial_{p} \bar{q}\right\rangle$ always share the sign). The thermodynamic effect $\left(-\left\langle\bar{\omega} \partial_{p} q^{\prime}\right\rangle\right)$ appears to play a secondary role in modulating the magnitudes of precipitation changes. The thermodynamic effect tends to enhance the magnitudes of precipitation changes when it is in the same sign with the dynamic effect and precipitation anomalies (see Figs. 5a and d). This situation happens in most parts (about 65\% in area coverage) of the Tropics (see Fig. 3), which is in agreement with the "wet-get-wetter" or "dryget-drier" mechanism. However, we do find some tropical areas (about 35\%) showing the opposite sign of thermodynamic effect to the dynamic effect and precipitation anomalies (see Figs. 5b and c). One particular example occurs in the eastern Pacific ITCZ where precipitation anomalies are mostly negative even though the mean vertical motion and precipitation are largely positive there. Instead, positive precipitation anomalies tend to appear near the equator just south of the eastern Pacific ITCZ. Since Pacific SST warming projected by CMIP5 models maximizes near the equator (see Fig. 6 for the pattern of SST warming projected by a multi-model mean of 17 CMIP5 models), it implies that precipitation changes over the equatorial eastern Pacific seem to comply more with the "warmer-get-wetter" mechanism rather than the "wet-get-wetter" mechanism. The smallness of horizontal moisture advection anomaly $\left(-\langle v \cdot \nabla q\rangle^{\prime}\right)$ in all sub-regions (see Figs. 5 and B1 for comparison) indicates a very minimal role of dry advection from non-convective regions (i.e., the "upped-ante" mechanism) in controlling the regional precipitation changes. It implies that, although the "upped ante" mechanism exists, its intensity is not strong enough to support precipitation changes, even at margins of convective zones.

Moreover, to understand how the convection structures might change in response to global warming in the aforementioned four sub-regions, Fig. 7 shows the differences of pressure velocity profiles between the periods 2006 - 2015 and 2090 - 2099 (the latter minus the former). In the mean ascending region with positive precipitation anomalies (see Fig. 7a), a notable enhancement of convection occurs near the tropopause, indicating a deepening of convection top. On the other hand, changes of pressure velocity are relatively modest below the tropopause. In the mean ascending region with negative precipitation anomalies (see Fig. 7b), the situation is reversed. A significant weakening of convection occurs throughout the troposphere, with only a slight enhancement of upward motion near the tropopause. In the mean descending region with positive precipitation anomalies (see Fig. 7c), a significant enhancement of upward motion occurs within the troposphere (i.e., convection is enhanced proportionally in troposphere), with a sizable descending anomaly near the tropopause. In the mean ascending region with negative precipitation anomalies (see Fig. 7d), a marked weakening of convection occurs throughout the troposphere without much change near the tropopause.

The above results clearly indicate that tropical regions with negative precipitation anomalies must be accompanied by a weakening of convection in the troposphere. However, convection structure changes responsible for positive precipitation anomalies vary depending on the regions. In the mean ascending region, the positive precipitation anomalies are associated mainly with the deepening of convection (i.e., a higher tropopause). In the mean descending region, the positive precipitation anomalies are a result of enhanced convection (upward motions) in the troposphere.

\section{CONCLUDING REMARKS}

Future tropical precipitation changes are investigated based on the multi-model means of 17 CMIP5 models outputs for the RCP8.5 experiments. This study shows that, while increases in CWV are relatively homogeneous in space, precipitation changes exhibit notable regional discrepancies with a mix of positive and negative precipitation anomalies over both the mean ascending and the mean descending regions. Because in nature there is always a lid to top the convection (due to much stable stratification in the 


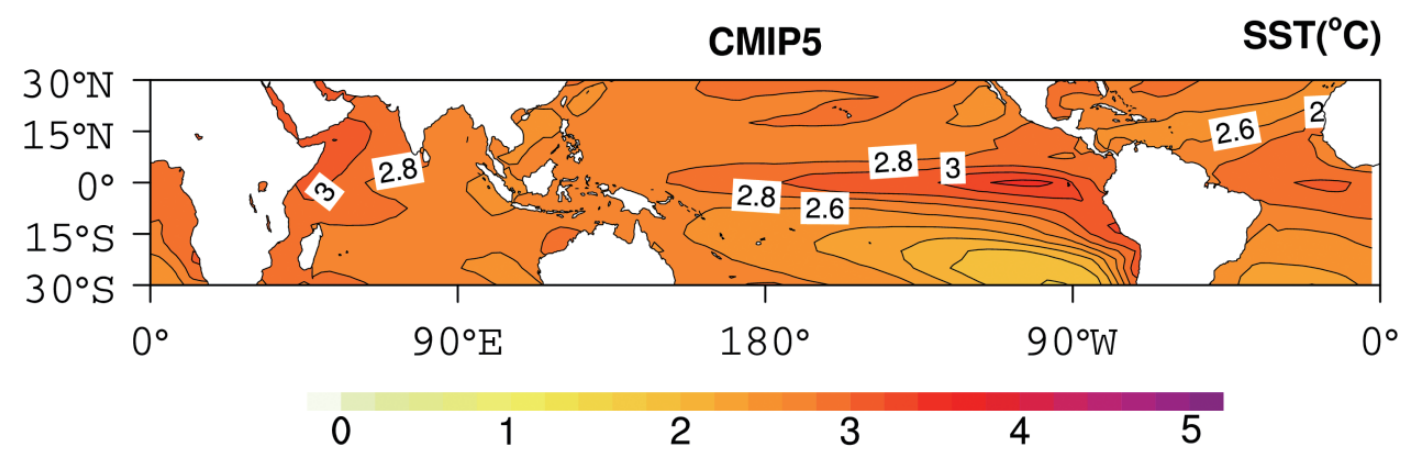

Fig. 6. Spatial pattern of SST warming (in ${ }^{\circ} \mathrm{C}$ ) between the two period $2006-2015$ and 2090 - 2099 simulated by a multi-model mean of 17 CMIP5 models under the RCP8.5 scenario.

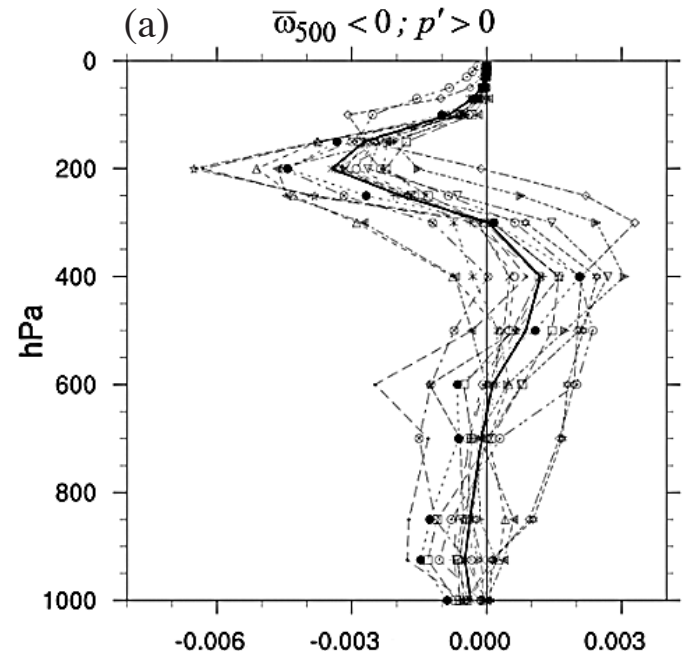

(c)

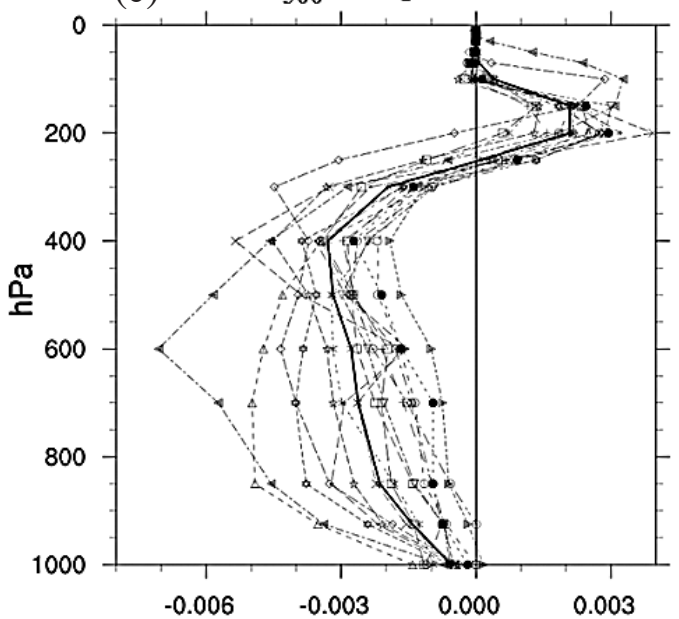

(b)

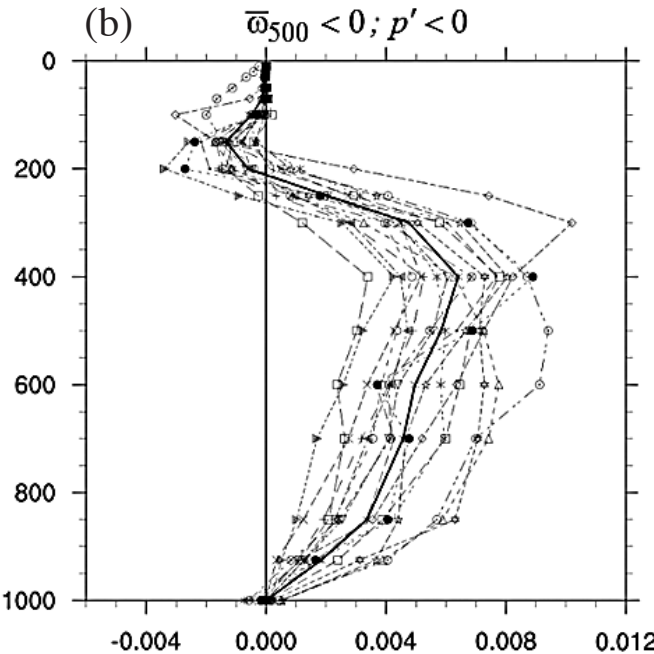

(d)

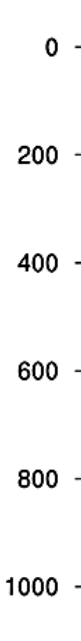

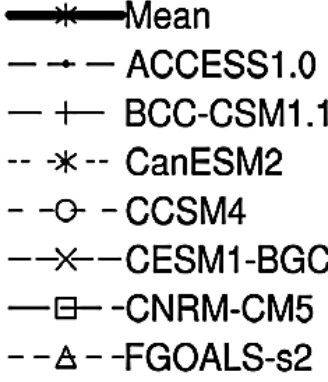

- $\nabla-$-FIO-ESM

$-\leadsto-$-GFDL-CM3

$-4-$ GISS-E2-R

$-\rightarrow---H a d G E M 2-C C$

- - --IPSL-CM5A-MR

-- -MIROC5

$-\diamond-$ MIROC-ESM

$-\otimes-$ MPI-ESM-LR

Fig. 7. Vertical profile of pressure velocity (in pa s $\mathrm{s}^{-1}$ ) differences between averages of 2090 - 2099 and 2006 - 2015 in (a) mean ascending region with positive precipitation anomaly $\left(\bar{\omega}_{500}<0 ; P^{\prime}>0\right)$, (b) mean ascending region with negative precipitation anomaly $\left(\bar{\omega}_{500}<0 ; P^{\prime}<0\right)$, (c) mean descending region with positive precipitation anomaly $\left(\bar{\omega}_{500}>0 ; P^{\prime}>0\right)$, and (d) mean descending region with negative precipitation anomaly $\left(\bar{\omega}_{500}>0 ; P^{\prime}<0\right)$. 
lower stratosphere), enhanced upward motions somewhere must be compensated by downward motions elsewhere, resulting in only modest changes of precipitation in the Tropics. A budget analysis of the moisture equation points out that changes of tropical precipitation are controlled mainly by the dynamics effect $\left(-\left\langle\omega^{\prime} \partial_{p} \bar{q}\right\rangle\right)$ not only over the mean ascending region but also over the mean descending region. The thermodynamic effect $\left(-\left\langle\bar{\omega} \partial_{p} q^{\prime}\right\rangle\right)$ plays only a secondary role in modulating the strength of precipitation anomaly. Its effect tends to enhance the magnitude of precipitation anomaly when it shares the same sign with the dynamic effect (e.g., Figs. 5a and d). This situation happens in the tropical western Pacific and Indian Ocean and most parts of the subtropical areas (see Fig. 3) where the "wetget-wetter" (or "dry-get-drier") mechanism seems to work properly. In regions where the dynamic and thermodynamic effects are of opposite signs (e.g., Figs. 5b and c), precipitation changes appear to comply more with other mechanisms (e.g., "warmer-get-wetter") rather than the "wet-get-wetter" mechanism. This situation happens in the equatorial eastern Pacific where greatest SST warming tends to occur under global warming.

Analyzing changes of convection structure further shows that regions with negative precipitation anomalies must be accompanied by a weakening of convection in the troposphere, indicating the dominant control of dynamic effect. However, different convection structure changes are involved in regions with positive precipitation anomalies. In the mean ascending region, the positive precipitation anomaly is associated with a deepening of convection; while in the mean descending region, the positive precipitation anomaly is a result of proportionally enhanced convection within the troposphere.

Moreover, simulations of regional precipitation changes are shown to be rather sensitive to model resolution, in particular, over the tropical eastern Pacific where gradients of thermodynamic fields (e.g., SST, specific humidity and precipitation) are relatively large compared to the tropical western Pacific and Indian Ocean. The above findings are based on area-mean results over the four sub-regions implied by Fig. 3. Further details may emerge when viewing convection and precipitation changes at local scales (e.g., Chou et al. 2006; Bui et al. 2016; Chen et al. 2016). This implies a pressing need for high resolution climate model experiments in order to provide a reliable projection of future precipitation changes in the Tropics.

Acknowledgements This work was sponsored by the Ministry of Science and Technology under Grants MOST1042111-M-008-026-MY2 and MOST105-2111-M-008-025MY3. The authors thank the CMIP5 climate modeling groups for producing and making available their model simulation outputs. The CMIP5 data were downloaded from the Earth System Grid at the Lawrence Livermore National Labora- tory, Department of Energy, USA (https://pcmdi9.1lnl.gov/ projects/cmip5/). The authors especially thank Prof. Simon Wang and another anonymous reviewer for their constructive comments to improve the quality of this manuscript.

\section{REFERENCES}

Allen, M. R. and W. J. Ingram, 2002: Constraints on future changes in climate and the hydrologic cycle. Nature, 419, 224-232, doi: 10.1038/nature01092. [Link]

Bui, H. X., J.-Y. Yu, and C. Chou, 2016: Impacts of vertical structure of large-scale vertical motion in tropical climate: Moist static energy framework. J. Atmos. Sci., 73, 4427-4437, doi: 10.1175/JAS-D-16-0031.1. [Link]

Chen, C.-A., J.-Y. Yu, and C. Chou, 2016: Impacts of vertical structure of convection in global warming: The role of shallow convection. J. Climate, 29, 4665-4684, doi: 10.1175/JCLI-D-15-0563.1. [Link]

Chou, C. and J. D. Neelin, 2004: Mechanisms of global warming impacts on regional tropical precipitation. $J$. Climate, 17, 2688-2701, doi: 10.1175/1520-0442(200 4)017<2688:MOGWIO>2.0.CO;2. [Link]

Chou, C., J. D. Neelin, J.-Y. Tu, and C.-T. Chen, 2006: Regional tropical precipitation change mechanisms in ECHAM4/OPYC3 under global warming. J. Climate, 19, 4207-4223, doi: 10.1175/JCLI3858.1. [Link]

Chou, C., J. D. Neelin, C.-A. Chen, and J.-Y. Tu, 2009: Evaluating the "rich-get-richer" mechanism in tropical precipitation change under global warming. J. Climate, 22, 1982-2005, doi: 10.1175/2008JCLI2471.1. [Link]

Held, I. M. and B. J. Soden, 2006: Robust responses of the hydrological cycle to global warming. J. Climate, $\mathbf{1 9}$, 5686-5699, doi: 10.1175/JCLI3990.1. [Link]

Huang, P., S.-P. Xie, K. Hu, G. Huang, and R. Huang, 2013: Patterns of the seasonal response of tropical rainfall to global warming. Nat. Geosci., 6, 357-361, doi: 10.1038/ ngeo1792. [Link]

Johnson, N. C. and S.-P. Xie, 2010: Changes in the sea surface temperature threshold for tropical convection. Nat. Geosci., 3, 842-845, doi: 10.1038/ngeo1008. [Link]

Liu, H.-W. and J.-Y. Yu, 2016: The relation between column water vapor and rainfall over tropical region. Atmos. Sci., 44, 135-148. (in Chinese)

Meehl, G. A., C. Covey, K. E. Taylor, T. Delworth, R. J. Stouffer, M. Latif, B. McAvaney, and J. F. B. Mitchell, 2007: The WCRP CMIP3 multimodel dataset: A new era in climate change research. Bull. Amer. Meteorol. Soc., 88, 1383-1394, doi: 10.1175/BAMS-88-9-1383. [Link]

Muller, C. J. and P. A. O'Gorman, 2011: An energetic perspective on the regional response of precipitation to climate change. Nat. Clim. Change, 1, 266-271, doi: 10.1038/nclimate1169. [Link]

Neelin, J. D., C. Chou, and H. Su, 2003: Tropical drought 
regions in global warming and El Niño teleconnections. Geophys. Res. Lett., 30, doi: 10.1029/2003GL018625. [Link]

O'Gorman, P. A. and C. J. Muller, 2010: How closely do changes in surface and column water vapor follow Clausius-Clapeyron scaling in climate change simulations? Environ. Res. Lett., 5, doi: 10.1088/17489326/5/2/025207. [Link]

Schmidt, G. A., M. Kelley, L. Nazarenko, R. Ruedy, G. L. Russell, I. Aleinov, M. Bauer, S. E. Bauer, M. K. Bhat, R. Bleck, V. Canuto, Y. H. Chen, Y. Cheng, T. L. Clune, A. Del Genio, R. de Fainchtein, G. Faluvegi, J. E. Hansen, R. J. Healy, N. Y. Kiang, D. Koch, A. A. Lacis, A. N. LeGrande, J. Lerner, K. K. Lo, E. E. Matthews, S. Menon, R. L. Miller, V. Oinas, A. O. Oloso, J. P. Perlwitz, M. J. Puma, W. M. Putman, D. Rind, A. Romanou, M. Sato, D. T. Shindell, S. Sun, R. A. Syed, N. Tausnev, K. Tsigaridis, N. Unger, A. Voulgarakis, M. S. Yao, and J. Zhang, 2014: Configuration and assessment of the GISS ModelE2 contributions to the CMIP5 archive. J. Adv. Model. Earth Syst., 6, 141184, doi: 10.1002/2013MS000265. [Link]

Seager, R., N. Naik, and G. A. Vecchi, 2010: Thermodynamic and dynamic mechanisms for large-scale changes in the hydrological cycle in response to global warming. J. Climate, 23, 4651-4668, doi: 10.1175/2010JCLI3655.1. [Link]

Stephens, G. L. and T. D. Ellis, 2008: Controls of global-mean precipitation increases in global warming GCM experiments. J. Climate, 21, 6141-6155, doi: 10.1175/2008JCLI2144.1. [Link]

Taylor, K. E., R. J. Stouffer, and G. A. Meehl, 2012: An overview of CMIP5 and the experiment design. Bull. Amer. Meteorol. Soc., 93, 485-498, doi: 10.1175/ BAMS-D-11-00094.1. [Link]

Trenberth, K. E., A. Dai, R. M. Rasmussen, and D. B. Parsons, 2003: The changing character of precipitation. Bull. Amer. Meteorol. Soc., 84, 1205-1217, doi: 10.1175/BAMS-84-9-1205. [Link]

Vecchi, G. A. and B. J. Soden, 2007: Global warming and the weakening of the tropical circulation. J. Climate, 20, 4316-4340, doi: 10.1175/JCLI4258.1. [Link]

Voldoire, A., E. Sanchez-Gomez, D. Salas y Mélia, B. Decharme, C. Cassou, S. Sénési, S. Valcke, I. Beau, A. Alias, M. Chevallier, M. Déqué, J. Deshayes, H. Douville, E. Fernandez, G. Madec, E. Maisonnave, M.-P. Moine, S. Planton, D. Saint-Martin, S. Szopa, S. Tyteca, R. Alkama, S. Belamari, A. Braun, L. Coquart, and F. Chauvin, 2013: The CNRM-CM5.1 global climate model: Description and basic evaluation. Climate Dyn., 40, 2091-2121, doi: 10.1007/s00382-0111259-y. [Link]

Wentz, F. J., L. Ricciardulli, K. Hilburn, and C. Mears, 2007: How much more rain will global warming bring?
Science, 317, 233-235, doi: 10.1126/science.1140746. [Link]

Xie, S.-P., C. Deser, G. A. Vecchi, J. Ma, H. Teng, and A. T. Wittenberg, 2010: Global warming pattern formation: Sea surface temperature and rainfall. J. Climate, 23, 966-986, doi: 10.1175/2009JCLI3329.1. [Link]

Zhou, Y. P., K.-M. Xu, Y. C. Sud, and A. K. Betts, 2011: Recent trends of the tropical hydrological cycle inferred from Global Precipitation Climatology Project and International Satellite Cloud Climatology Project data. J. Geophys. Res., 116, D09101, doi: 10.1029/2010JD015197. [Link]

\section{APPENDIX A. PATTERNS OF CWV AND PRECIPITATION CHANGES IN 17 CMIP5 MODELS}

Figure A1 displays spatial patterns of column water vapor (CWV) and precipitation changes in 17 CMIP5 models over the period 2006 - 2099. Despite the very different magnitudes, all CMIP5 models generally show a very similar pattern of CWV trends under global warming in the Tropics, i.e., a relatively homogeneous increase of CWV with slightly larger magnitudes over the warm ITCZs (Intertropical Convergence Zones). In contrast, changes of precipitation appear to be highly regional dependent. Positive and negative precipitation trends coexist not only over the warm ITCZs but also over the subtropical descending regions and the eastern Pacific cold tongue. The regional discrepancies of precipitation changes in response to global warming imply the important role of dynamic responses (e.g., convection structure changes) in controlling regional precipitation changes in the Tropics.

\section{APPENDIX B. GEOGRAPHICAL DISTRIBUTIONS OF THE PRECIPITATION BUDGET}

Figure B1 displays geographical distributions of budget results for the precipitation anomaly budget Eq. (3). We find that the term associated with moisture change $\left(-\left\langle\bar{\omega} \partial_{p} q^{\prime}\right\rangle\right.$, thermodynamic effect) agrees quite well with the "wet-get-wetter" or "dry-get-drier" hypothesis, i.e., enhanced precipitation appears over ITCZ regions and reduced precipitation over non-ITCZ regions (see the top panel of Fig. B1). Although the term associated with convection change $\left(-\left\langle\omega^{\prime} \partial_{p} \bar{q}\right\rangle\right.$, dynamic effect) generally tends to offset the thermodynamic effect, however, its geographical pattern does not exactly follow the domain of ITCZ (see the $2^{\text {nd }}$ panel of Fig. B1), resulting in a complex regional precipitation change pattern shown in Fig. 3. For example, strong positive anomalies over the equatorial Pacific cover both the mean ascending (ITCZ) and mean descending (non-ITCZ) regions. The horizontal moisture advection $\left(-\langle v \cdot \nabla q\rangle^{\prime}\right)$ and evaporation $\left(E^{\prime}\right)$ terms (see the $3^{\text {rd }}$ and bottom panels of 


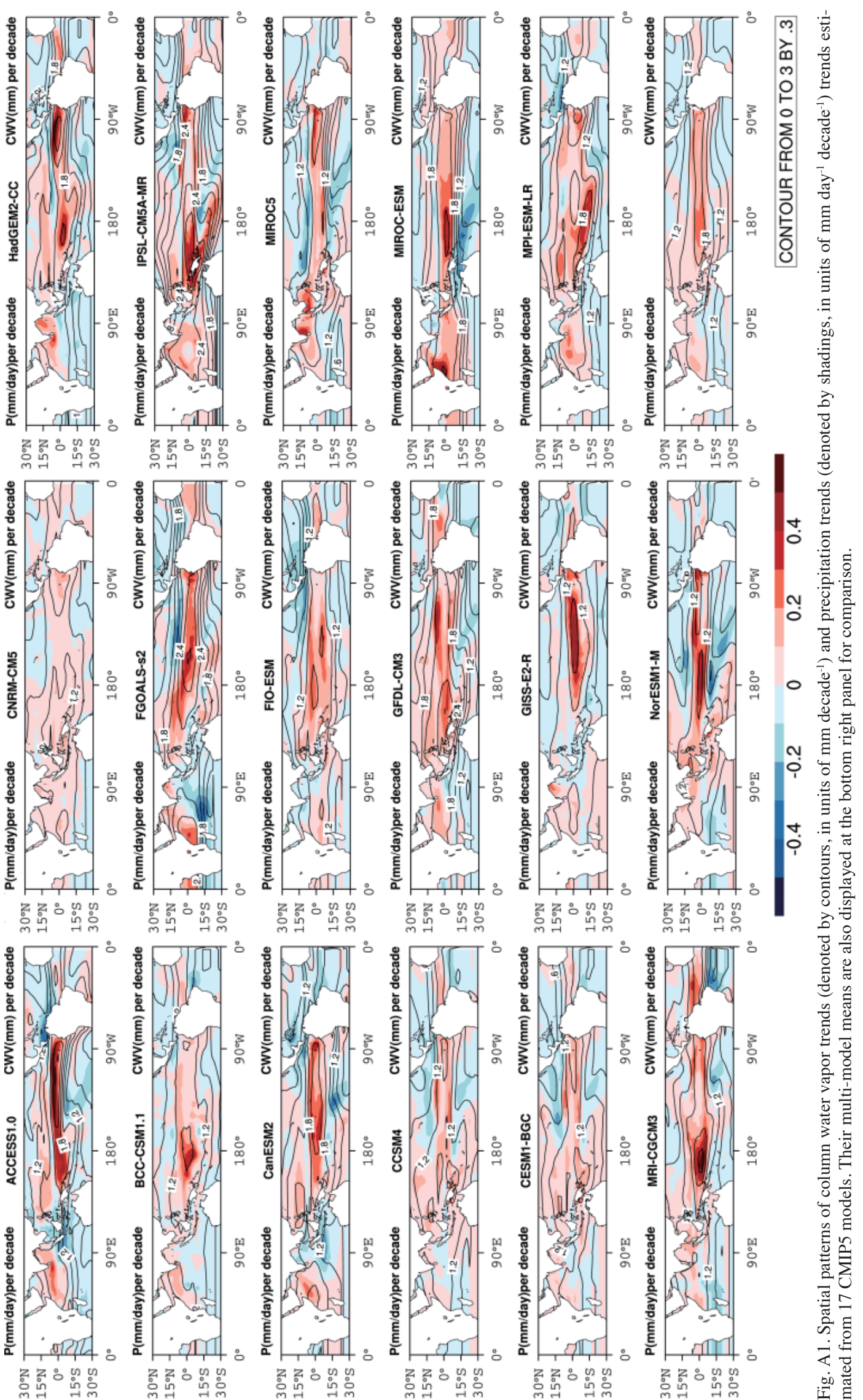



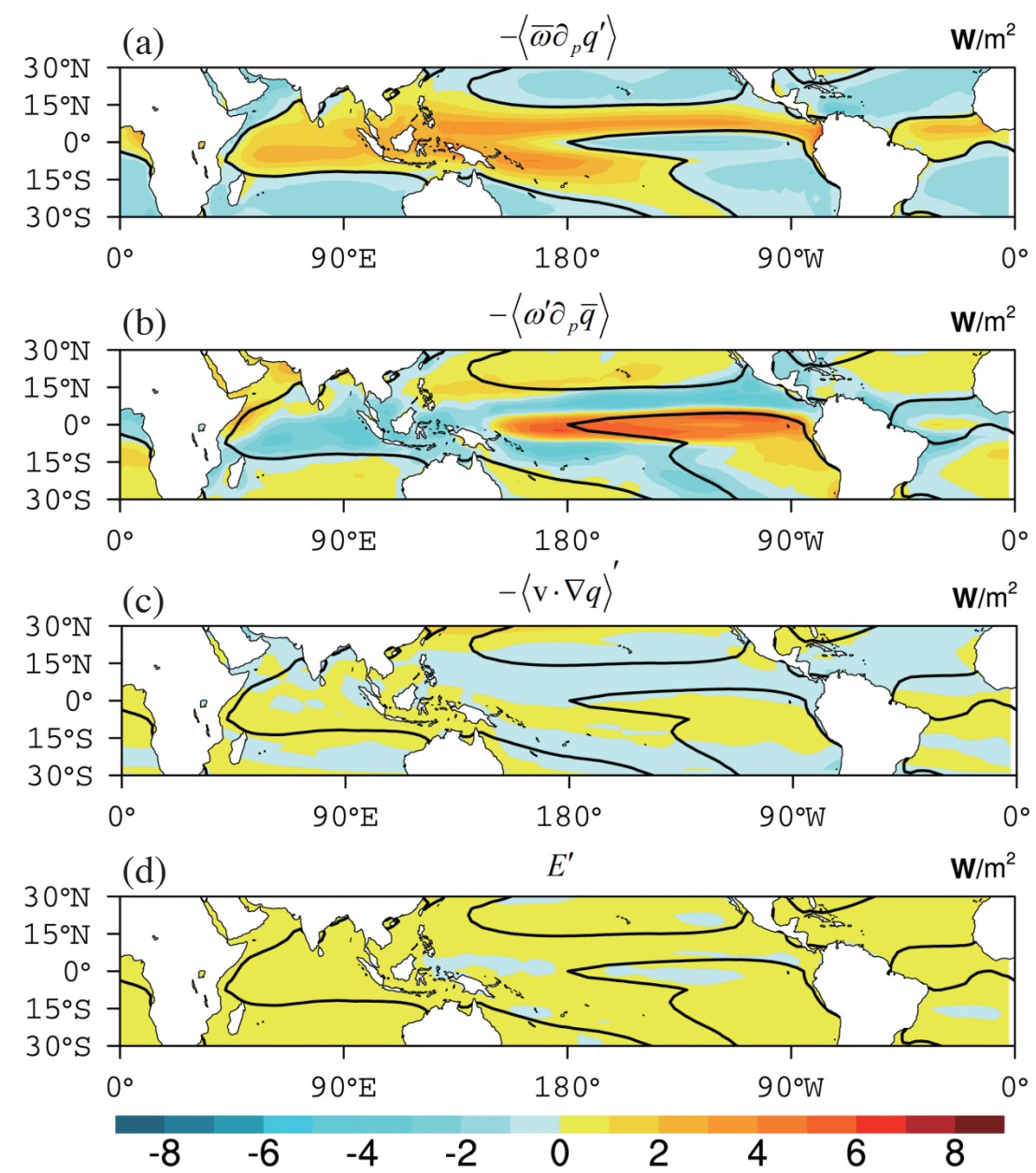

Fig. B1. Geographical distributions of budget terms (denoted by shadings, in units of $\mathrm{W} \mathrm{m}^{-2}$ ) derived from multi-model means of $17 \mathrm{CMIP5}$ models . (a) Anomalous vertical moisture advection due to change in moisture stratification, (b) anomalous vertical moisture advection due to change in convection, (c) horizontal moisture advection anomaly, and (d) evaporation anomaly. The thick solid lines represent the $\bar{\omega}_{500}=0$ contours.

Fig. B1) appear to play modest roles in the precipitation anomaly Eq. (3) as their magnitudes are much smaller compared to the first two terms, consistent with the results shown in Fig. 5. In summary, while the sign and intensity of precipitation anomalies is controlled by the dynamics effect, the applicability of "wet-get-wetter" or "dry-get-drier" hypothesis relies very much on the thermodynamic effect.
The "wet-get-wetter" or "dry-get-drier" hypothesis can be used to account for changes of tropical precipitation only when dynamic and thermodynamic effects work together, accounting for about two thirds of the total tropical area (see Fig. 3 for comparison). The remaining area disobeying the above hypothesis shows the thermodynamic effect opposing to the dynamic counterpart. 